\title{
CORRESPONDENCE
}

Correspondents are asked to be brief

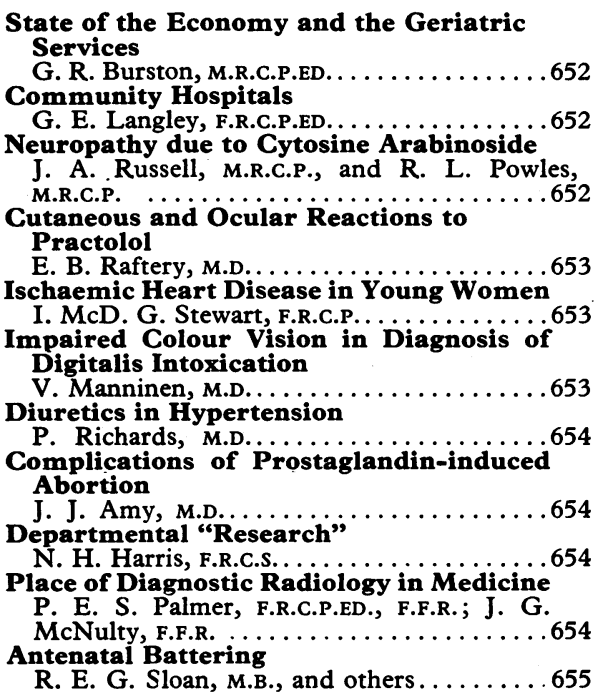

Deaths during Dentistry

P. J. Tomlin, F.F.A.R.C.s.; E. O. Evans, F.R.C.G.P.; L. B. C. Lewis, M.B., B.D.S. . . . . 655

Dexamethasone in Malignant Hyperpyrexia Flight Lieutenant D. G. Raitt, M.B., D.A., and Group Captain A. J. Merrifield, F.F.A.R.C.S. . 656

Florence Nightingale's Illness

Sir George Pickering, F.R.C.P., F.R.S. . . . . . . 656

Safety and Fibreoptic Bronchoscopy

J. B. MacDonald, M.R.C.P............6656

Sticky Eye in the Newborn

Elisabeth Rees, M.D., and D. Hobson, M.D. . 656

New Curriculum

B. Isaacs, F.R.C.P.GLAS.

Tuberculosis and Renal Amyloidosis

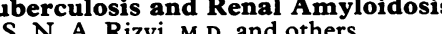

S. N. A. Rizvi, M.D. and others..........6657

Medical Centre for Unsettled Young People
Anne Davies, B.A..................65

Anne Davies, B.A.................

Intrathoracic Mesothelioma

J. S. M. Leung, F.R.C.S.ED., and S. T. Tang . . 657

Complication of Austin Moore Prosthesis

O. N. Vyas, F.R.C.S., and A. K. Varshneya

F.R.c.s. .....................658

"Locked-in" Syndrome

N. Shannon, F.R.C.S.ED.; D. L. J. Freed, M.B.658
Kidneys for Transplantation

W. J. Atkinson, F.R.C.S. . . . . . . . . . .6658

Choice of Contraceptives

D. B. Jelliffe, M.D., and E. F. P. Jelliffe,

M.P.H. . . . . . . . . . . . . . . . 658

Full View of the Road

A. J. Phillips, M. PHIL., F.B.o.A. . . . . . . . . 658

Eye Colour and Oculocardiac Reflex

E. N. S. Fry, F.F.A.R.C.S., and B. J. P. Hall-Parker,

L.M.S.S.A., D.o...................658

How to Close a Hospital

Wendy E. Love, F.R.C.o.G. . . . . . . . . . . . 658

Payment for F.P.A. Reports

P. O'Flynn, M.B................6658

\section{Consultant Contract}

I. K. Mathie, M.R.c.o.G.; J. F. Patrick,

F.R.C.S.ED.; A. H. W. Bain, M.B.; M. J.

Lockwood, M.B.................6658

Common Approval

A. R. Gaymer, M.B., and others . . . . . . . 659 Sanctions

W. R. Blatchley, M.B.; R. F. Gunstone,

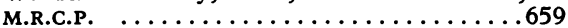

Government and Profession

R. D. Turner, M.B.............660
SIR,-As a geriatrician I am profoundly concerned at the state of the economy and the parlous state of the National Health Service. It seems to me that the major crisis in the hospital service is no longer bricks and mortar but simply pairs of hands to do the job. One gathers that the social services departments are cut to the absolute minimum expansion, and that all the propaganda and publicity together with new legislation heaped on their shoulders means they cannot possibly hope to cope.

Family practitioners whom I would normally regard as honest and competent seem to be sending elderly people into hospital with at times what can be described only as a totally fictitious medical diagnosis. The reason seems to be to obtain relief from an intolerable domestic situation in which the old person finds herself and from which neither she, the district nurse, home help, nor family doctor can escape. These old people rapidly get better with simple care and perhaps virtually nothing in the way of medicine. But when one tries to restore them to the community or seek alternative care within it such a resistance is put up or they return to such a hostile atmosphere that they inevitably break down again. This seems in turn to be leading to increasing disharmony among the various groups who are trying to provide against all the odds some service for this large, very frail, and grossly neglected section of society. Several of my colleagues and, indeed, I myself have now reached a point where the ability to care for genuine patients in hospital is jeopardized by this vicious circle. The simple "pair-of-hands" syndrome is so bad that at times it is positively dangerous to admit proper patients because they cannot receive the care that should be their right.
One sees very clearly that more and more elderly people are going to be admitted to hospital for very dubious "medical" reasons - not only in geriatric wards but also in general medical and surgical wards-because the community cannot support them and that the hospital will not be able to return them to the community because of this lack of support. A hospital is just about the most expensive "hotel" available, and I see us paying enormous sums to keep people in the wrong place at the wrong time for entirely the wrong reasons but with no obvious escape from the situation.-I am, etc.,

G. R. BuRSTON

Southmead Hospital,

Bristo

\section{Community Hospitals}

SIR,-Unlike Mr. H. T. John and his colleagues (30 November, p. 534) I welcome the Department's document on community hospitals.

Devon, like the Bath Health District, has many local hospitals which serve isolated rural communities or small towns. In this county there are also proportionately more old people than in any other and at present the mentally ill among them who require long-term inpatient treatment in a psychiatric hospital must receive it in one hospital situated up to 50 miles $(80 \mathrm{~km})$ from their homes and relatives. I therefore welcome the opportunity to offer to these predominantly demented patients a local community service that will minimize their detachment from others and distribute more evenly the responsibility for their care. Professional standards will be maintained by the continued integration of peripheral units into the team practice of the consultant psychiatrists concerned. This is surely an area for "close relationship between the consultant and family practitioner and mutual understanding of each other's problems and the patient's needs."

If it is felt that work with the elderly would result in "greatly diminishing interest and morale" and restriction in the range of work (and it must be accepted that this is a common attitude), then this like any other problem in, for example, medicine or surgery must be examined objectively in the light of the patients' best interests. It should not be accepted as an unremediable fact of life which underlines status differences between different professional disciplines and patient age groups. - I am, etc.,

Exe Vale Hospital,

Exminster Branch,

Exminster, Exeter

G. E. LANGLEY

\section{Neuropathy Due to Cytosine Arabinoside}

SIR,-We wish to draw attention to a possible neurological complication of treatment with the antineoplastic agent cytosine arabinoside (ARA-C). This is probably the most widely used drug in adult acute leukaemia, but we are not aware of other published reports of peripheral neuropathy associated with this drug, and a recent review on the neurotoxicity of antineoplastic agents makes no mention of it. ${ }^{1}$

We here report two patients who developed symptoms of a sensory peripheral neuropathy following treatment of acute myelogenous leukaemia with ARA-C.

Case 1-A 49-year-old man (weight $80 \mathrm{~kg}$ ) was diagnosed as having acute myelogenous leukaemia in November 1970. He received induction chemotherapy consisting of ARA-C intravenously eight-hourly for 48 hours (total dose $4 \mathrm{mg} / \mathrm{kg}$ ) followed 48 hours later by daunorubicin $1.5 \mathrm{mg} / \mathrm{kg}$ intravenously and a further three daily injections of 
ARA-C (total dose $6 \mathrm{mg} / \mathrm{kg}$ ). This treatment was repeated three weeks later and he had passed into full remission by January 1971. Remission was maintained by weekly immunotherapy with B.C.G and allogeneic leukaemia cells and monthly courses of chemotherapy. The chemotherapy consisted of five daily injections of ARA-C 1-2 mg/kg together with either a single injection of daunorubicin $1.5 \mathrm{mg} / \mathrm{kg}$ or 6 -thioguanine $2 \mathrm{mg} / \mathrm{kg}$ per day for five days. After four such courses he developed burning sensations in his feet which followed each subsequent course of treatment but gradually improved between courses. Because this occurred after every course it could be related only to the ARA-C. Chemotherapy was stopped on 26 November 1971 after a total dose of $7 \mathrm{~g}$ of ARA-C, but he continued to complain of intermittent but he continued to complain of intermittent burning or tingling sensations in his feet, sometimes knee and occasionally affecting the fingers. There knee and occasionally affecting the fingers. There
has never been any objective neurological abnorhas never been any objective neurological abnor-
mality and his symptoms have continued to improve slowly, but they are still present $2 !$ years after stopping chemotherapy.

Case 2-A 52-year-old man with acute myelogenous leukaemia (weight $70 \mathrm{~kg}$ ) had similar induction chemotherapy to Case 1 and after $600 \mathrm{mg}$ of ARA $\mathrm{c}$ hother $600 \mathrm{~m}$ of ARA-C he complained of numbness and paraesthesiae involving all four limbs. After four courses of treatment he passed into full haematological remission and was then given eight weeks' treatment with 6-thioguanine and cyclophosphamide. This was immediately followed by a single injection of daunorubicin $100 \mathrm{mg}$ and ARA-C $130 \mathrm{mg}$. He then stopped all chemotherapy and was maintained in complete remission on immunotherapy alone. During this period his neurological symptoms improved, though he still complained of painful intermittent paraesthesiae in a glove-andstocking distribution extending to the elbows and knees and intermittent stabbing pains throughout the body. He relapsed after seven months of immunotherapy and was treated with two courses immunotherapy and was treated with two courses of high-dose ARA-C (total $20 \mathrm{mg} / \mathrm{kg}$ ) followed by single intravenous injection of adriamycin $(2 \mathrm{mg}$ $\mathrm{kg}$ ). These courses were given 10 days apart and following the second course his paraesthesia became worse. Thereafter aggravation of his neurological symptoms was always associated with ARA-C. A second complete remission lasted only three months in spite of monthly courses of ARA-C $2 \mathrm{mg} / \mathrm{kg}$ for five days and 6-thioguanine alternating with daunorubicin. Reinduction chemotherapy included ARA-C ( $180 \mathrm{mg} / \mathrm{daily}$ for five days) following which his neurological symptom rapidly became worse and their character changed. $\mathrm{He}$ continued to have numbness extending up to the elbows and knees and tingling sensations in the fingers, but he also had burning or aching pains with the same distribution. At no time auring the with the same distribution. At no time auring the neurological abnormalities. He died five months neurological abnormalities. He died

Both of these patients had symptoms characteristic of a sensory peripheral neuropathy which developed during cytotoxic therapy for acute myelogenous leukaemia. In both cases the only drug consistently related with deterioration of the neurological symptoms was ARA-C. Case 1 would appear to have developed these symptoms after a total of $4 \mathrm{~g}$ of ARA-C, but because of their subjective nature the time of onset was difficult to determine precisely. Case 2 developed his neurological symptoms after a total dose of $600 \mathrm{mg}$ of ARA-C. Both patients reported improvement in the absence of chemotherapy, but Case 1 still experiences some paraesthesiae two and a half years after his last dose of ARA-C.

During the past six years at least 350 new adult patients with leukaemia have been treated with ARA-C in our departments, of whom approximately $40 \%$ have had main tenance ARA-C after remission. This mean that the incidence of problems due to this particular complication is very low. Never theless, there is no question that the quality of life was impaired considerably in both the patients reported here by their neurological symptoms. We would be most interested to know if other workers who use this drug frequently have noticed a similar association.
We wish to to thank Dr. T. McElwain for permission to publish the second case report.

-We are, etc.,

Immunotherapy Department,

Royal Marsden Hospital,

Sutton, Surrey

J. A. RuSSELL

R. L. Powles

I.C.R.F. Department of Medical Oncology, St. Bartholomew's Hospital, don E.C.1 Weiss, H. D., Walker, M. D., and Wiernik, P. H.,
New England fournal of Medicine, 1974, 291,
75 and 127.

Cutaneous and Ocular Reactions to Practolol

SIR,-I was very interested to read the paper by Dr. R. H. Felix and others ( 9 November, p. 321). I would like to bring up to date a quotation from a publication of mine $^{1}$ which appeared in their discussion section.

I reported an incidence of 3-4\% of positive antinuclear factor (A.N.F.) titre in patients on practolol, but in a retrospective survey of 67 patients taking practolol for angina we found that seven had an A.N.F. titre greater than $1 / 40$, an incidence of $11 \%$. In a prospective survey of 71 patients who were treated with practolol for angina or dysrhythmias the A.N.F. titre was greater than $1 / 40$ before treatment in only one $(1.4 \%)$. After an average of six months of treatment this had risen to five $\left(11^{\prime}(1)\right)$ and one of these patients developed a florid disseminated lupus erythematosus (D.L.E.).

A prospective study of 50 patients receiving oxprenolol for the treatment of hypertension revealed no instance of a raised A.N.F. titre before or after treatment for a period of three months. The same was true for 24 patients taking propranolol for hypertension. There have been no instances of D.L.E. syndrome in these two groups of patients.

These observations suggest that practolol is unique among the commonly used betablocking agents in producing the D.L.E. syndrome and in producing a rising A.N.F. titre.-I am, etc.,

Northwick Park Hospital,

E. B. RAFTERY

1 Raftery, E. B., in New Perspectives in Betablockade International Symposium, p. 239.
Denmark. Ciba Laboratories, 1972.

\section{Ischaemic Heart Disease in Young Women}

SIR,-In his analysis of ischaemic hear disease in young women Dr. M. F. Oliver (2 November, p. 253) claims that there had been a hypertensive "risk factor" in $40 \%$ of those who suffered myocardial infarction. This figure, I would suggest, is misleading since the evidence, much of it retrospective is insufficient to establish that these women were hypertensive before their infarctions.

An unstated proportion of them were "recorded as having hypertension" for no bette reason than that they had been under treatment for this condition apparently at the hands of their family doctor, there being no reference to any earlier attendance in Dr. Oliver's department. In others the diagnosis was made on the strength of a clinic finding of a diastolic pressure that remained at a level of $100 \mathrm{~mm} \mathrm{Hg}$ or more during a period of ten minutes rest on one occasion. A single such reading in women aged up to 45 may suggest but cannot justify a diagnosis of hypertension. Still less is it relevant that in the remainder of this group the pressure was found to have risen into similar levels within a year after the infarction.

It is said of the allegedly hypertensive patients who sustained infarcts that $25 \%$ also had left ventricular hypertrophy, the implication being that here was further proof of pre-existing hypertension. We are not told how the hypertrophy was recognized. But in patients who had survived, or were about to suffer, infarction the assumption would appear to be precariously based. Radiologically it is seldom possible to make an exact distinction between minor cardiac enlargement caused by hypertension and that also found in normotensive patients with myocardial change secondary to coronary artery disease. Nor do electrocardiographic tracings afford any precise means of distinguishing between the two, especially in terms of S-T depression and $T$ inversion, the only abnormalities that are cited.

That hypertension after infarction was later found to be a "potent risk factor" is scarcely surprising since it was imposing strain upon a myocardium that was already damaged, a simple sequence of cause and effect unrelated to those obscure and diverse influences that determine the slow development of coronary atheroma together with its allied, yet nonetheless distinct, occasional complication of myocardial infarction.-I am, etc.,

I. MCD. G. STEWART

Victoria Hospital,

Blackpool

\section{Impaired Colour Vision in Diagnosis of} Digitalis Intoxication

SIR,-Measurement of the serum level of digoxin provides an accurate estimate of the diagnosis of digitalis intoxication. ${ }^{12}$ Measurements are, however, time-consuming and need expensive instrumentation. Simple methods for the confirmation of digitalis intoxication would be welcome.

Various visual complaints are frequently seen as initial signs of digitalis toxicity. ${ }^{3}$ We have tested colour vision in five consecutive ambulant patients in whom the suspicion of digitalis intoxication arose because of clinical signs like loss of appetite, nausea, abdominal discomfort, extrasystoles, or unexplained feeling of sickness. In two patients barium meal examination, carried out because of loss of weight and constant abdominal discomfort, had revealed no signs of organic disease. In the examination of colour vision Ishihara tables (24 plates, 1974) were used. The patients (two male, three female, aged 61-78) were receiving $0 \cdot 15$ to $0.75 \mathrm{mg}$ of digoxin daily and two with heart failure were also receiving frusemide with potassium chloride; four had atrial fibrillation. The serum potassium level was normal $(4-2-4 \cdot 6 \mathrm{mmol} / \mathrm{l})$ in all five. The serum digoxin was only $1.3 \mathrm{ng} / \mathrm{ml}$ in one patient but ranged from 2.1 to $3.2 \mathrm{ng} / \mathrm{ml}$ in the other four.

When first studied all five patients had some degree of difficulty in seeing the plates for red-green vision. All also complained of indistinct vision of objects. When the test was repeated two weeks after diminishing the digoxin dose none of the subjects had 